\title{
BARRIERS HINDERING THE EFFECTIVE INTEGRATION OF ORPHANED CHILDREN LIVING IN CHILD-HEADED HOUSEHOLDS INTO EXTENDED FAMILY FOLDS
}

\section{Assim Alpaslan, Luzile Florence Nziyane \\ INTRODUCTION AND PROBLEM FORMULATION}

Patel (2005:167) states that the family is a basic unit of society and plays an important role in the lives of all people, especially children. However, the HIV and AIDS epidemic has devastated the family structure, which is already strained by other detrimental factors such as urbanisation, poverty, political and economic migration, and the changing roles of women (Amoateng \& Richter, 2007:1-3).

As a leading cause of adult mortality, AIDS has led to a world-wide trend whereby many children have become orphans. While some of them are often absorbed by their extended families, several do slip through this safety net and end up living by themselves or with siblings in CHHs (Foster, 2004:3).

The existence of the $\mathrm{CHH}$ could be an indication that the extended family system is breaking down (MacLellan, 2005:2). Germann (2005:68) states that as the extended family safety net weakens, children end up in a variety of extremely vulnerable circumstances, such as being at risk of sexual abuse by neighbours or relatives, malnutrition, having their education seriously jeopardised because of an inability to pay school fees, child prostitution and child trafficking (Rantla, Siwani \& Mokoena, 2002:57-62).

Foster (2000:56) highlights the fact that in order to protect these children from slipping through the safety net, it is important to understand the extended family system's capacity to absorb orphaned children with a view to developing appropriate methods to support this traditional method of orphan care. It is in the light of this that the researchers became motivated to conduct this study to develop an in-depth understanding of the barriers that hinder effective integration of orphaned children into extended families.

\section{RESEARCH QUESTION AND GOAL}

Fossey, Harvey, McDermott and Davidson (2002:723) state that in qualitative studies qualitative research questions are used instead of hypotheses to "identify the initial focus of the inquiry". The research question posed to focus this study was: From the perspectives of children who are heading $\mathrm{CHHs}$, members of the extended families related to these children, and the social workers rendering services to these children, what are the barriers that hinder orphaned children living in CHHs from being absorbed into their families?

The goal for the study was accordingly set as follows: To discover and develop an in-depth understanding of the barriers that hinder effective integration of CHHs into extended families from the perspectives of the extended families, children who are heading the $\mathrm{CHH}$ and social workers.

The information generated from this research will contribute to the knowledge base of social work pertaining to the topic, and inform policy and social work interventions directed at these client systems. 


\section{RESEARCH APPROACH AND METHODOLOGY}

A qualitative approach was followed to realise the goal of the study. The motivation for employing this approach was informed by Green and Thorogood's $(2009: 5,38)$ view that, if the goal of your study is "to develop an in-depth understand[ing of] the perspectives of participants, explore the meaning they give to phenomena, or observe a process in depth, then a qualitative approach is properly appropriate". The qualitative approach was well suited to this research as it fostered a better understanding of the barriers that hinder the integration of CHHs into their extended family folds from the perspective of the abovementioned participant groups.

Within the qualitative approach, an explorative, descriptive and contextual research design was followed. The exploratory design was used as little was yet known about the barriers that hinder the integration of CHHs into extended families (Neuman, 2006:33). The descriptive design was employed to describe aspects identified as a result of the exploration initially executed for the study (Neuman, 2006:34-35). A contextual research design was employed to understand the meanings of the participants' life accounts within their specific social context (Neuman, 2006:158).

The purposive sampling technique was employed for this study to seek participants who had first-hand knowledge about, and who were being directly affected by, the phenomenon investigated and were thus "information rich" to be able to provide the information required to answer the research questions posed at the outset of the study (Fossey et al., 2002:726; Donalek \& Soldwisch, 2004:356). The sample was comprised of orphaned children who were heading CHHs, extended family members related to the children participating in the study, and social workers who were rendering social work services to these client systems in Bushbuckridge, Mpumalanga province.

The researcher responsible for the fieldwork used semi-structured, face-to-face interviews to collect the data from the participants. To focus the discussion, the following question was posed to the respective participants belonging to each interest group:

Question for children heading the CHH: What worries you or makes you afraid about the idea of going to stay with your relatives?

Question for the extended families: What are the factors/things hindering you from taking these orphaned children into your home?

Question for social workers rendering services to $\mathrm{CHH}$ : From your point of view, what are the factors hindering the effective integration of $\mathrm{CHH}$ into extended families?

Since this study was qualitative in nature, the sample size was not determined at the outset of the study, but the principle of "data saturation" was applied to determine the sample size in the end. The researcher conducting the fieldwork continued interviewing participants until she was empirically confident that no new insights were being gained from the interviews (Donalek \& Soldwisch, 2004:356). At that point the data-collection process was discontinued and all data that had been digitally voice recorded (with the consent of the participants) were transcribed from the voice recorder word for word in Xitsonga and later translated into English for dataanalysis purposes. Ten children heading households, eight family members from eight extended families related to the children, and seven social workers were interviewed for the study.

The descriptive analysis technique of Tesch's eight steps (as cited in Creswell, 2003:192-193) was employed to analyse the data to reduce the voluminous information that had been gathered 
into themes, sub-themes and categories, as well as to generate patterns and relationships among the data in a coherent and systematic manner.

Guba's model for the trustworthiness of qualitative data as outlined by Krefting (1991:215-222) was applied to verify the data. Research findings were assessed against Guba's four aspects that seek to ensure trustworthiness, namely: truth value, applicability, consistency and neutrality. The credibility of the research findings was also ensured through the use of an independent coder who had experience in qualitative research methods, and who conducted the data analysis independently. Findings from the independent coder's report were compared with the findings of the researcher who conducted the fieldwork during a consensus discussion facilitated by the researcher not engaged in the fieldwork conducted.

According to Yegidis and Weinbach (2002:26), most of social work research depends on human beings to provide the information required for knowledge-building. Researchers therefore have an ethical obligation to ensure that participants are treated well and their health and wellbeing are safeguarded. It was for this reason that the following ethical considerations were upheld in conducting the study: adequately informing potential participants about the research project before obtaining their consent to participate (consent was obtained in writing from the children heading the $\mathrm{CHH}$, the extended family members and the social workers), safeguarding the privacy and confidentiality of participants and the data, management of information, the use of a digital voice recorder to ensure accuracy of data collected, referral of participants who required social work intervention, and debriefing of the participants.

\section{DISCUSSION OF FINDINGS}

The discussion on the research findings will be presented in two sections. The first section will focus on the geographical area where the study was conducted and the demographic data of the participants who partook in this study. The second section will present the theme, sub-themes and categories which emerged from the processes of data analysis and the consequent consensus discussion.

\section{GEOGRAPHICAL AREA AND THE DEMOGRAPHIC DATA ON THE RESEARCH PARTICIPANTS}

Bushbuckridge Local Municipality is in the north-eastern part of Mpumalanga province. The HIV prevalence rate in this Local Municipality increased from 6\% in 1996 to $24.6 \%$ in 2006 and 28.2\% in 2007 (Mpumalanga Department of Health and Social Services, 2007). Bushbuckridge was selected because a very large number of $\mathrm{CHHs}$ were reported in this local municipality. The Community Survey (2007) indicates that out of 124,595 households in Bushbuckridge, approximately 4,377 of these households were headed by children in 2007 . When compared with all the local municipalities in Mpumalanga province, Bushbuckridge had the highest prevalence of $\mathrm{CHH}$, followed by Nkomazi Local Municipality with 2,355 $\mathrm{CHH}$ (Community Survey, 2007).

Table 1 shows the demographic data of children heading households. 


\section{TABLE 1}

DEMOGRAPHIC DATA OF THE CHILDREN HEADING HOUSEHOLDS

\begin{tabular}{|l|c|c|c|c|c|}
\hline $\begin{array}{l}\text { Participant's } \\
\text { pseudonym }\end{array}$ & $\begin{array}{c}\text { Age of the } \\
\text { participant }\end{array}$ & $\begin{array}{c}\text { Age of } \\
\text { commencement as } \\
\text { head of the } \\
\text { household }\end{array}$ & Gender & Grade & $\begin{array}{c}\text { Number of } \\
\text { children being } \\
\text { taken care of by } \\
\text { the child head }\end{array}$ \\
\hline Andries & 16 & 13 & Male & 09 & 02 \\
\hline Godfrey & 16 & 15 & Male & 10 & 02 \\
\hline Collen & 16 & 13 & Male & 10 & 03 \\
\hline Fikile & 16 & 14 & Female & $\begin{array}{c}\text { Drop-out } \\
\text { Grade } 08\end{array}$ & 04 \\
\hline Peter & 16 & 13 & Male & 09 & 02 \\
\hline Pretty & 16 & 14 & Female & 09 & 03 \\
\hline Philile & 17 & 13 & Female & 10 & 02 \\
\hline Ntombi & 17 & 15 & Female & 10 & 03 \\
\hline Musa & 17 & 15 & Male & 10 & 02 \\
\hline Rhandzu & 17 & 14 & Female & 11 & 02 \\
\hline
\end{tabular}

The dispersion of scores in Table 1 on the ages of children heading households at the time of conducting the study indicates that the children's ages ranged from 16 to 17 . There were six children who were 16 years old and four children who were 17 years old. The Children's Amendment Act (Act No. 41 of 2007: Sec 137(1)(c)) stipulates that a child who is 16 years old may be considered as head of a household and bear rights and responsibilities as a caregiver. It is evident from the ages of the children that they were within the age limit for being heads of these households, according to this Act.

Table 2 shows the demographic data of the extended family members who participated in the study.

TABLE 2

DEMOGRAPHIC DATA OF THE EXTENDED FAMILY MEMBERS

\begin{tabular}{|c|c|c|l|l|}
\hline $\begin{array}{c}\text { Participant } \\
\text { Code }\end{array}$ & $\begin{array}{c}\text { Age of the } \\
\text { participant }\end{array}$ & Gender & \multicolumn{1}{|c|}{$\begin{array}{c}\text { Relationship to the } \\
\text { CHH }\end{array}$} & Occupation \\
\hline A & 65 & Female & Maternal grandmother & Pensioner \\
\hline B & 29 & Female & Maternal aunt & Unemployed \\
\hline C & 40 & Female & Maternal aunt & Unemployed \\
\hline D & 55 & Female & Maternal aunt & Unemployed \\
\hline E & 67 & Female & Maternal grandmother & Pensioner \\
\hline F & 59 & Female & Maternal grandmother & Unemployed \\
\hline G & 42 & Male & Paternal uncle & Administrator \\
\hline H & 65 & Female & Maternal grandmother & Pensioner \\
\hline
\end{tabular}


Looking at these figures, it is evident that many of the $\mathrm{CHH}$ participants in the study had relatives who were in the stages of middle adulthood and older adulthood as compared with the young adulthood stage (which was represented by only one relative). Table 2 also shows that four of the extended family members of the children heading CHHs were unemployed and were depending on their husbands, who were earning an income. One extended family member was formally employed as an administrator, while the remaining three extended family members were receiving government social grants.

Table 3 shows the demographic data of social workers who participated in the study.

TABLE 3

DEMOGRAPHIC DATA OF SOCIAL WORKERS

\begin{tabular}{|c|c|c|c|c|}
\hline $\begin{array}{c}\text { Participant } \\
\text { Code }\end{array}$ & $\begin{array}{c}\text { Age of the } \\
\text { participant }\end{array}$ & Gender & $\begin{array}{c}\text { Number of } \\
\text { years in social } \\
\text { work practice }\end{array}$ & Educational level \\
\hline L & 34 & Female & 07 & Bachelor's degree in Social Work \\
\hline M & 26 & Male & 03 & Bachelor's degree in Social Work \\
\hline N & 31 & Female & 07 & Bachelor's degree in Social Work \\
\hline O & 36 & Female & 07 & Bachelor's degree in Social Work \\
\hline P & 24 & Female & 03 & Bachelor's degree in Social Work \\
\hline Q & 33 & Female & 04 & Bachelor's degree in Social Work \\
\hline R & 36 & Female & 07 & Bachelor's degree in Social Work \\
\hline
\end{tabular}

The dispersion of scores in Table 3 above on the ages of the social workers indicates that their ages ranged from 24 to 36 . Six of the social workers were females and one was male. Table 3 also shows that all social workers had three years and more experience in social work practice. In this regard their broader knowledge and experience of rendering generic social work services added value to the credibility of the findings of this study.

\section{BARRIERS HINDERING EFFECTIVE INTEGRATION OF CHH INTO EXTENDED FAMILY FOLDS}

The findings will be presented according to the major theme (i.e. barriers hindering effective integration of $\mathrm{CHHs}$ into extended family folds) with its accompanying sub-themes and categories which emerged from the processes of data analysis undertaken on the transcribed interviews. Complementing storylines from the transcripts will also be presented, compared and contrasted with current theories and the literature (Creswell, 2003:196).

The barriers that hindered effective integration of CHHs into the extended family folds will be presented according to the following sub-themes:

- Poverty-related challenges as barriers to integrating the $\mathrm{CHH}$ into the extended family;

- Relational and family-related challenges as barriers to integrating the $\mathrm{CHH}$ into the extended family;

- Cultural factors as barriers to integrating the $\mathrm{CHH}$ into the extended family;

- Child-related circumstances as barriers to integrating the $\mathrm{CHH}$ into the extended family; 
- Limitations in social work services and service delivery to orphaned children and extended families as barriers to integrating the $\mathrm{CHH}$ into the extended family.

Each of the above sub-themes will now be presented and compared with the current theories and the literature.

\section{Sub-theme 1: Poverty-related challenges as barriers to integrating the $\mathrm{CHH}$ into the extended family}

This sub-theme was divided into various categories.

\section{Category: Inability to meet fundamental needs for subsistence as a barrier to integrating the $\mathrm{CHH}$ into the extended family}

Phiri and Tolfree (in Foster et al., 2005:17) noted that families are increasingly feeling the strain of shouldering a disproportionate burden in absorbing more children into their homes as they are stifled by pervasive poverty which pushes them into living in extremely difficult circumstances. The ability to meet children's fundamental needs plays a critical role in supporting and maintaining a family. The extended family's inability to provide food and clothing was perceived as a hindrance for some of the extended families to absorb orphaned children into their homes. Two of the extended family members attested to this as follows:

I won't be able to buy them food...

... we wanted their grandmother to stay with them, but it failed because she doesn't get a grant...

Some of the children also mentioned that the challenges associated with inadequate food could be a hindrance for their extended families to absorb them. Two children verbalised it as follows:

I think it will be a problem for them [to absorb us into their homes] because they might think that we are finishing their food when we eat their food...

At my grandmother's place, everyone eats his/her own food because they are many and there are many children, so my aunts and uncles won't want to stay with us because each buys his/her own food for their own children ... even if we may want to go and stay with them, it means that we will have to eat our own food.

Most of the social workers confirmed that extended families that experienced financial constraints were unable to absorb orphaned children; however, the knowledge that there is state support motivated them to absorb the children. The following excerpts from two social workers attest to this:

Financial constraint is the most important thing, but when they become aware that there is a grant, foster care grant, they become more willing to take the children.

... most people [relatives of orphaned children] here depend on child support grants.

\section{Category: Unemployment of relatives as a barrier to integrating the $\mathrm{CHH}$ into the extended family}

Unemployment of relatives was identified as a major hindrance in the family integration of orphaned children living in CHHs. The children mentioned that their relatives were unable to take them into their homes as they were not working. The following storyline from one of the children attests to this: 
... my other relatives are not working ...

Most of the extended families expressed strong feelings regarding unemployment as a deterrent to their taking in orphaned children as illustrated in the following two excerpts:

I would take these children; the only challenge would be that I am not working and I don't get a grant, because they will be too many and I would not be able to buy enough food for all of them because I don't receive a grant and I am not working.

If I was ... working, I wouldn't have any problem; I would take these children and live with them ...

One of the extended family members was unable to contain her pain associated with her inability to take in the children as demonstrated in the following excerpt:

If I was employed I would take them. ... so, the problem is that I am not working [tears rolling down from her eyes].

One of the social workers (through the following statement) also confirmed that unemployment played a major role in the integration of $\mathrm{CHH}$ :

Unemployment as well is a big problem.

\section{Category: Inadequate accommodation as a barrier to integrating the $\mathrm{CHH}$ into the extended family}

This study found that relatives with inadequate accommodation were unable to take in orphaned children. Some of the children mentioned that the relatives' houses did not have enough living space to accommodate both the extended family's members as well as the orphaned children, as demonstrated by the following excerpts from two children's responses:

I think that we will be [too] many at her house and it won't be able to accommodate us properly ...

... my grandmother, her house is small and it won't be able to accommodate us all.

The shortage and the inability of the extended families' living space to accommodate their members as well as the orphaned children were also mentioned by some of the social workers:

... relative's houses are overcrowded...

... the issue of accommodation; most of the people in our communities have houses that are not complete; and you find that the children sleep in a room that is used as a bedroom, a kitchen and everything, and you find that they are congested in that room, and you find that there are six children sleeping in that room ... accommodation is a problem as well.

In some instances some of the children's houses were in a better condition compared to their relatives' houses and this was a hindrance as children were discouraged from being integrated into those relatives' homes, as the following comment from one of the social workers indicates:

... the relative's house is not safe, it is a mud house which can fall anytime or water comes in when it rains; so it makes the children refuse to be integrated with their relatives because their house is better than that of their relatives.

These findings are supported by Rantla et al. (2002:21) who, in their pilot project on orphans and extended families' reintegration, found that children were not willing to be integrated with 
relatives as relatives were poorer than themselves and in some instances the orphaned children's homes were structurally more solid and beautiful than the relatives' mud houses.

\section{Category: Abuse of grants by the extended families as a barrier to integrating the CHH into the extended family}

The issue of relatives abusing orphaned children's grants came out very strongly from the social workers as a hindrance to the family integration of orphaned children living in $\mathrm{CHH}$. Most of the social workers interviewed mentioned that due to poverty-related challenges, relatives were motivated by social grants to take in orphaned children with a view to providing for their own families' needs. In utilising the foster child grants, relatives were found to be prioritising their own financial needs rather than those of the orphaned children and this discouraged orphaned children from living with their relatives, as demonstrated in the following excerpts from the social workers:

... these days you find that a person decides without the consent of the other family members because of the grant, and you find that when she gets that grant she uses it for herself and not for the children's benefits.

... [Some] get the foster care grant and in the long run they abuse the money, they are no longer taking care of the children, because those extended families are having their own children to look after; so you find that they use the money for their own children and not the orphaned children.

In some instances relatives threaten or mistreat children when they confront the situation with a view to trying to address it as is illustrated by the following statement from one of the social workers:

... relatives do not use the money for the benefits of the children, and when the children protest, they say that "we will give you the money and you will see what you can do with the money"...

One child (who was the only recipient of the foster child grant of all the children participating in the study) also cited inadequacy and possible abuse of her foster child grant as a hindrance to her living with her grandmother and she expressed herself as follows:

It will also give us problems because it means that we will have to use our money to help in buying food, because for instance, if we were to live with my grandmother, my uncles [grandmother's children] are not working; this will result in having our money having to buy them food and it won't be enough to buy us things that we want as well as building material to finish building the house...

\section{Category: Inability to take in more orphaned children as a barrier to integrating the CHH into the extended family}

The reluctance of the extended families to integrate orphaned children who were living in CHHs was characterised by their inability to take on further responsibility for accommodating more children in their homes. Most of the participants mentioned that taking in orphaned children caused a burden on the relatives who were already struggling to take care of their own families. These findings are consistent with findings by Gilborn, Nyonyintono and JagweWadda (2001:17), who found in their study that the capacity of guardians to provide care to orphaned children is affected by the number of dependent children that relatives have in their care. The following excerpts from two of the children confirm this: 
... my aunt's husband doesn't want us ... they also have their own children to take care of so we were like causing a burden to them.

Two years ago we used to live with my aunt [mother's elder sister] and her husband. Her husband didn't want us to live at his home, and he was constantly complaining about food that it was too much for him to buy us food and his family as well.

The overwhelming responsibility which extended families experience when they take in orphaned children was also confirmed by one of the social workers as follows:

... relatives feel that it will be a burden to them to take the children into their homes ...

You find that they have their own families, their own children that they need to take care of and if they add these ones, they feel that it is going to be too much for them ...

Some of the extended family members who were already living with other orphaned children were unable to take in more children as the responsibility of taking care of all children in their care was perceived as overwhelming, as the following comments from some of the extended family members reveal:

For me to take these children and stay with them it won't be possible because I am now living with four other orphaned grandchildren ..."

... if I take Philile ${ }^{I}$ and her sibling it means that I will be having eight grandchildren to look after and this will give him [husband] a big problem; because he is not even able to buy clothes for my two grandchildren."

\section{Sub-theme 2: Relational and family-related challenges as barriers to integrating the CHH into the extended family}

Relational and family-related challenges will also be discussed according to separate categories.

\section{Category: Conflict between maternal and paternal families as a barrier to integrating the $\mathrm{CHH}$ into the extended family}

The research findings of this study suggest that conflicts between maternal and paternal families were a result of a deviation from cultural practices related to the recognition of traditional marriages. Foster (2000:56) states that in most traditional African cultures marriage is decided upon a bride price (i.e. lobola in isiZulu), which in the past was paid in the form of cattle to the bride's family by the husband's family. The payment of this bride price led to the recognition and legitimisation of future children, which also ensured that these children became the responsibility not only of the father but of his family as well. Some of the social workers (quoted below) mentioned that the non-recognition of such marriages by the extended families led to conflicts between maternal and paternal families and becomes an obstacle that hinders the integration of orphaned children into their extended families.

The people here, you find that they live together without lobola. So you find that the maternal family refuses the paternal family to take the children because the children's father didn't pay lobola; and you find that children end up living alone ...

${ }^{1}$ Not her real name. 
[The maternal family] say that the paternal family didn't pay lobola and the maternal family refuses that the paternal family should take the children, you see. So, the children remain in the middle because two families are fighting over them ...

One of the extended family members attested to the fighting between paternal and maternal relatives over children. He shared the experience that had led him not to take his deceased brother's children into his home as follows:

... these children have two sets of relatives. They have their maternal relatives and they have us ... When these children's parents died, there were lot of fighting in between because this one wanted to take the children and that one wanted to take the children. It was like a tug of war, and it made me think that if I take the children, the other relatives will come and say that I'm ill-treating the children, and they can do better than what I'm doing; especially because the government gives grants to such children ... the other relatives ... think that I will benefit from the grant, or when they [referring to the orphaned children] get food parcels ... so when the food parcels add to the food that I'm buying, the relatives think that I will be having a lot of food in my house. So, this made me decide not to take the children into my home.

\section{Category: Past relational feuds as a barrier to integrating the $\mathrm{CHH}$ into the extended family}

Bad relationships that existed between deceased parents of orphaned children and the extended family members hindered the integration. Most social workers mentioned that past relational feuds were a major obstacle which they observed during their contact with $\mathrm{CHH}$ and their extended family members. They shared their experiences as follows:

... family relations become a hindrance for relatives to take the child.

... even when we ... plead with them to accommodate the children, they refuse, and they often cite issues like they were not getting along well with the children's parents - things like that. In some families you find that they never had a good relationship with the children's parents when they were still alive; so it is not easy for them to take the children ...

Some of the children concurred with the social workers viewpoints above and stated:

...grandmother didn't love us even when my mother was still alive; so she won't be able to love us now that my mother has passed away.

Even when my mother was still alive, they didn't love her, hence they don't help me when I ask for their help.

The following comment from one of the social workers provides an explanation for the source of the bad relations between the relatives and the deceased parents:

Most of these bad relations are caused when the father insists to marry the children's mother even when his family is against it. This makes the mother of the children to cut ties between her and her in-laws and sometimes even tell her husband to stop contacting his family; so because of the lack of contact between them, it causes a stumbling block because when they pass away. The matter continues between the children and their relatives and causes the children not to want to live with them, and also the relatives sometimes refuse to take the children saying that the children have their mother's attitude and they don't want to live with them. 
This is confirmed by one of the extended family members:

...even when my sister was still alive, the paternal family didn't like her, they didn't want her to be their daughter-in-law. They don't talk to us and we don't talk to them either. The problem is that they are not helping these children. I don't have a problem if they don't talk to us but these are their children and they don't want to stay with them.

The findings above are consistent with findings by Nkomo (2006:73-74) that unresolved family disputes and past histories result in children being neglected and rejected by their relatives.

\section{Category: Interference by, and criticism from, relatives towards relatives willing to integrate children from $\mathrm{CHH}$ as a barrier to this integration}

Interference by, and criticism from, other relatives towards relatives who were willing to integrate orphaned children caused a hindrance for the willing relatives from absorbing the children into their homes. Some of the extended family members mentioned that lack of cooperation from other relatives in raising the orphaned children made it difficult for them to maintain the integration of the children, as demonstrated by the following excerpts:

Sometimes it is difficult because the children are a combination of two surnames [i.e. maternal and paternal surnames]; and you find that the two families are not cooperative. When you scold the child, the maternal family doesn't give you support and they tell the children that you are ill-treating them meanwhile you are trying to help the children to do the right thing.

Sometimes the children's uncles [deceased mother's brothers] do come to me and blame me that what I'm doing is not right when I scold the children. They dictate to me how I should discipline the children.

In some instances, the interference and criticism stemmed from community members. One of the extended family members testified as follows:

Sometimes it is not only maternal relatives; other people in the community as well will interfere.

\section{Category: Abuse of the orphaned children by the extended family as a barrier to integrating the $\mathrm{CHH}$ into the extended family}

Abuse of orphaned children by their extended family members was identified by some of the participants as a hindrance to effective integration of $\mathrm{CHH}$ into extended family folds. These findings concur with the survey conducted by Howard, Phillips, Matinhure, Goodman, McCurdy and Johnson (2006:7) on barriers to and incentives for orphan care where primary caregivers in rural Zimbabwe identified maltreatment of orphaned children by their new families as a barrier to orphan care. One of the extended family members attested to this as follows:

Some relatives, you find that they [relatives] ill-treat orphaned children just because they buy them food to eat ...

With reference to this category, two social workers spoke vividly about how some of the extended family members abused orphaned children with whom they were living:

... they [relatives] ... abuse the children. The child's work will be to clean, and there is no moral support to the child. They don't care about the child. 
... many children are abused ... when we integrate them with relatives, many children are abused ...

In some instances extended family members forced the orphaned children to miss out on school in favour of their own children as demonstrated by the following comments from two social workers:

... relatives are ill-treating the children and you find that their children go to school but she expects the orphaned children to do this and that and then miss school.

... abuse by relatives. When the relative's child drops out of school; the orphaned child is also expected to drop out and to look for a job.

In other instances extended family members abused orphaned children physically, emotionally or sexually, which hampers the integration of the children from the $\mathrm{CHH}$ into the extended family's fold as was illustrated by the following statements made by the social workers:

... the children were staying with their sister [in foster care], but the sister in the long run abused the children ... physically and emotionally. She was not buying them food or clothes, she beats them and ... eish ... [while shaking her head].

... the uncle was raping the girl repeatedly ...

\section{Category: Unsuitability of relatives to integrate orphaned children living in $\mathrm{CHH}$ as a barrier to integrating the $\mathrm{CHH}$ into the extended family}

The following excerpts from some of the social workers gave rise to this category:

... unsuitability of relatives to take care of the children hinders integration.

Sometimes you find that the child chooses the relative she wants to be integrated with and you find that in terms of the Child Care Act ... you find that her choice contradicts with the Act because the child must stay in an environment which is conducive, the place must be safe.

Some of the extended family members concurred with the fact that some of the relatives that were "available" to take in orphaned children were not suitable for the integration of the children. They said:

... their aunt ... is unable to take care of her own children ... when she comes home [from her workplace], she doesn't even ask how her sister's children are, or whether they have food to eat.

We once requested their uncle to go and stay with them [the orphaned children] and we found that he was not taking good care of them and we decided that he should go back to his own place to live there.

\section{Category: Lack of contact with the extended family as a barrier to integrating the CHH into the extended family}

This hindrance resulted in poor relationships between the children and their relatives which would be necessary to facilitate integration. Foster (2000:58-59) confirms that children from families that have little contact with their extended families are at risk of being abandoned by their relatives when they become orphaned. The following comments from two extended family members confirm this: 
... there is no relationship between the paternal relatives and these children. They don't visit the children and these children don't visit them as well; hence it won't be possible that these children can go and live with them ...

The children's paternal grandparents are not near, they live very far ... They do not have love towards these children and it is clear that they won't treat the children well, because they are unable to build a relationship with these children ...

Some of the children heading the $\mathrm{CHH}$ echoed the sentiments of the extended family members above as indicated by the following utterances:

Since my father's burial in 2006, they have never been to visit us although they are not staying far from us ... From my mother's side we are only left with my grandmother who does not visit us as well. She ... does not care much about us ...

... My grandmother didn't love us ... she doesn't come to visit us to check if we have food or whether we are in good health. Even now that I took my younger brother to hospital because of the rash, she has never been to check on us to see how he is doing ...

\section{Sub-theme 3: Cultural factors as barriers to integrating the CHH into the extended family}

Cultural factors which were identified as barriers to family integration of orphaned children living in $\mathrm{CHH}$ will be presented next as separate categories.

\section{Category: Patriarchal social organisation as a barrier to integrating the $\mathrm{CHH}$ into the extended family}

Foster (2000:56) states that most traditional African cultures are built around patrilineal kinship systems. Such a kinship system (i.e. the extended family system) is made up of all members from multiple generations who belong to the same patrilineage mainly through marriage. When parents belonging to this patrilineal kinship system die, the paternal aunts and uncles traditionally take on the care-giving functions for the children. The findings of this study concurred largely with this; some of the extended family members confirmed that relatives who belong to the same patrilineage with the orphaned children were the rightful owners of those children and were expected to assist the children. Storylines referring to this included:

... if you have relatives they are supposed to help you.

... and according to the law, they [paternal grandparents] are the rightful owners of these children.

One of the children attested as follows:

... they are my relatives and they are the people ... when I lack something were supposed to help me...

The patrilineal system was identified as an obstacle to the family integration process as children who did not belong to the same patrilineage were rejected by the relatives concerned. In many instances, the aunts (i.e. the deceased mother's sisters) were willing to absorb their deceased sister's children, but their husbands were not willing to integrate the children because the children did not belong to the husbands' patrilineage. The following excerpts from two children attest to this: 
My aunts indicated that they are married and their husbands won't allow us to stay with them.

My aunt also told us that she is afraid of her husband to take us because he doesn't want us to live with them. She said that he wants to stay with his relatives only.

One of the social workers referred to this:

... the husband [of the deceased mother's sister] didn't want the children to come and stay with them in his family, but the wife wanted to take the children ... because they are her late sister's children.

Some of the extended family members (i.e. the aunts) also confirmed that their husbands were not willing to absorb the orphaned children because of the patriarchal social organisation:

If it was in my power, I would have taken these children to stay with me; so, this is not my home, I am in other people's home by marriage; and my husband is the one who is working, and he doesn't want to take them.

... it is not easy for me to take him [orphaned child] to stay with me because this is not my home, I am married here...

\section{Category: Cultural beliefs as a barrier to integrating the $\mathrm{CHH}$ into the extended family}

Cultural beliefs which relatives and orphaned children upheld with regard to the deceased parents' wishes were identified as a hindrance to the integration process. There is a saying in Xitsonga: "Ra mufi a ri tluriwi", which means that no one should deviate from the deceased person's wishes which he/she made when he/she was still alive. Some of the social workers mentioned that this saying hindered relatives from absorbing the orphaned children as their deceased father had mentioned (when he was still alive) that he wanted his children to remain in the house and the relatives were afraid to defy his wishes. The following statements testify to this:

... there was a relative who wanted to take them but was afraid of the deceased father of the children. She attempted to take the children once; after she took the children, the father of the children came to her through a dream at night and say: "Betty, what did I say about my children, didn't you hear me!' So, she had no choice but to take the children back to their own home. So, cultural beliefs also hinder effective integration, because you find that relatives are willing to take the children but they are afraid.

Other things you find that the children don't want to stay with the relatives because their deceased parents told them that they should live in their home, they mustn't leave ... The relatives mustn't take them ... they feel that when they leave their parent's house they won't get blessings from their deceased parents ...

Foster, Makufa, Drew and Kralovec (1997:165) made similar findings in that some orphaned children prefer to remain in the child-headed or adolescent-headed household to fulfil promises which they made to their dying parents. 


\section{Sub-theme 4: Child-related circumstances as barriers to integrating the CHH into the extended family}

The participants identified specific barriers (discussed below) that were related to the orphaned children living in $\mathrm{CHH}$ which hindered the effective integration of these children into their extended family folds.

\section{Category: Different lifestyles (children coming from homes with different rules) as a barrier to being integrated into the extended family}

Previous exposure to family rules and parenting style affected effective integration of children into extended family folds. Some of the extended family members found it difficult to integrate orphaned children who were raised in families that had adhered to a set of family rules and a parenting style that was different from that of the extended family members. The following storylines speak of this:

... it is difficult to take them because they will come with their own family rules.

... it's just that these children grew up in a different family... different family rules ... only girls that does household chores, so if ... the boys are expected to mop the floors and cook and do such things ... the boys will feel that I am ill-treating them and I am making them slaves.

One child stated that having a lifestyle that is different from their relatives would cause tension if they were integrated with their relatives:

... like now maybe if the church that they go to is not the same with the one that I go to ... like for instance if they go to this church and I go to that church, it will be a problem because if I go and stay with them and still continue to go to that church, they will keep quiet and not say anything about it meanwhile they are talking behind my back that I am not good.

\section{Category: Children's preference not to be integrated as a barrier to being integrated into the extended family}

The participants, especially the children, identified the following reasons that led to the children's choice to remain in the $\mathrm{CHH}$ :

- Children having a place to stay on their own;

- Children having support in staying on their own;

- Children wanting to keep and care for parents' property;

- Children preferring an independent life style;

- Children's previous negative relationships and experiences with the extended family;

- Children's fear and experiences of unfair treatment;

- Negative attitudes of children of extended family towards orphans from $\mathrm{CHH}$;

- Children's unwillingness to relocate;

- Children's unwillingness to be split amongst relatives. 


\section{Category: Children's unacceptable behaviour as a barrier to being integrated into the extended family}

Phiri and Tolfree (in Foster et al., 2005:18) assert that caring for someone else's children, especially children who have had psychologically damaging experiences, is not the same as caring for one's own child, as these damaging experiences may manifest as emotional or behavioural problems in the lives of the orphaned children. The inability of the extended family members to deal with the children's behavioural problems discouraged them from absorbing the children. The following two comments from the social workers attest to this:

... the children are uncontrollable in a sense that you find that they have behavioural problems which are unacceptable to the relatives. You find that relatives feel as if it won't be easy for them to mould the children and make them adapt to the kind of behaviour that is seen as acceptable to that relative's family.

Most of the time children, especially teenagers, do not relate well with the relatives' parental style as some of the children want to do as they please anytime they want to. As they know that their parents are deceased, they feel that no one can tell them what to do including their relatives because they are not their biological parents.

Some of the extended family members mentioned that the way in which the orphaned children responded when they spoke with them made it difficult for them to stay with these children, as demonstrated by the following two comments:

It was difficult for me to stay with them because when they started going out with boys they replied me things that were not good. Their answers were not good because they answered me knowing that I am not their mother, I am their grandmother. They answered me badly ... I won't be able to stay with them.

Sometimes you might find that they don't reply you well when you talk to them, and this can make you angry ... Sometimes when you scold him he says: "You are not my father, don't you see your children; there they are, why don't you scold them?"

\section{Category: Orphaned children's ages as a barrier to being integrated into the extended family}

The age of the orphaned children also played an important role in determining family integration. Some of the extended family members mentioned (as illustrated in the comments below) that it was difficult for them to integrate older children, as they felt that it would not be easy for them to assist such children to adapt to the extended family's rules.

It is easy if children are still very little, but if they are grown up it is difficult ...

... it is better to stay with a child who is below 10 years because he doesn't have much memory of his parents and he might end up thinking that you are his real parent ...

... if the child is 15 years old ... it is difficult to take them because they will come with their own family rules...

These findings are consistent with findings in the study conducted by Howard et al. (2006:5) that some caregivers took orphaned children's age and gender into consideration before they made a decision on fostering orphaned children. 


\section{Category: Stigmatisation of orphaned children as a barrier to being integrated into the extended family}

One of the social workers identified the stigma related to the death of orphaned children's parents as a barrier to family integration of orphaned children. Relatives who lacked knowledge on HIV prevention feared that the orphaned children could be HIV positive and they could contract the virus from the children. She stated:

... in some cases but they are few, you find that maybe the parents were ... maybe they died of HIV-related diseases, and you find that some of the children that are left behind are also HIV-positive, so you find that it is the stigma attached to HIV; some that do not have knowledge on how HIV is contracted, you find that they have fear that they could get infected, things like that; to some families it is like that.

This finding is supported by Foster et al. (1997:163), who note that some relatives may be concerned about integrating orphaned children when they suspect that the parent died from AIDS-related disease as they fear that they might contract HIV from the children, or they may be afraid that bringing the children into their home may lead to stigmatisation.

\section{Sub-theme 5: Limitations in social work services and service delivery towards orphans and extended families as barriers to integrating the $\mathrm{CHH}$ into the extended family}

The participants identified limitations (presented as categories below) relating to social work services and service delivery as hindrances hampering integration of children from CHHs into the extended families.

\section{Category: Social workers' high caseloads hinder efforts and initiatives for integrating the $\mathrm{CHH}$ into the extended family}

The large number of cases requiring foster care services hinders the integration. Most of the social workers mentioned that as a result of the high caseloads they were unable to do their work appropriately. This resulted in placing children with unsuitable relatives, which in turn led to the disintegration of such placements, as illustrated by the following excerpts:

... as social workers we need to first investigate more or assess more because this is lacking in our work currently because of high caseload of foster care cases, and according to me I think we don't do it properly ... because we end up putting a child with a relative that is not suitable due to lack of time to do thorough investigations. If we can investigate thoroughly on who should take the children, we can avoid placing children with wrong people who ill-treats them.

Although we do supervision but it is not enough and it is not done properly because we have a huge backlog of foster care placements. It's like supervision versus backlog ... we are not able to do proper checks ...

One of the social workers mentioned that social workers were unable to provide counselling to orphaned children as a result of the high caseloads by stating:

The role of the social worker that we were supposed to do but we are not able to do because of the backlog is counselling. Obviously when children lose their parents they need counselling, but we are not doing it because of the backlog. 
Category: Pressure from management to place orphaned children into foster care as a hindrance to integrating the CHH into the extended family

As a result of pressure from management to expedite placements of orphaned children, social workers were unable to provide optimal social work services as they were forced to focus on meeting targets that were set for a particular month. The following two statements point to this:

... there is pressure from our supervisors that we need to push numbers of foster care placements and we want to reach the target that is set for a month.

Because right now we are just doing it just for the sake of investigating and get excited that I have placed so many children with their relatives on that particular month, whereas the person whom I have given the children to is not a suitable person.

\section{Category: Lack of adequate resources as a hindrance to integrating the $\mathrm{CHH}$ into the extended family}

One of the social workers mentioned that lack of adequate resources compromised the quality of social work services and service delivery in integrating the children from the $\mathrm{CHH}$ into the fold of the extended family. The following storyline bears testimony to the lack of resources:

... we don't have enough resources as well, like when I want to type a report, I need to go to ... office to do that because I don't have a computer. We have only one car which is used by four social workers and eight social auxiliary workers. We are not able to do our job effectively. We just come to work because we need money but our working conditions are not good.

\section{Category: Lack of monitoring and support to extended families living with orphaned children as a hindrance to integrating the CHH into extended families}

This hindrance was identified as a major detriment to the family integration process. Some of the social workers mentioned that their inability to supervise and support these placements had resulted in orphaned children being abused by their relatives and this hindered the family integration of orphaned children, as demonstrated by the following excerpts:

Another thing that I think is the role of the social worker in this [integration] process is supervision of the placements. Right now it [referring to supervision of placements] is also a challenge. Supervision is not happening currently. Once we place children it ends there. You find that months or even years can pass without the social worker knowing what is happening in a particular family.

... and this [referring to lack of supervision and support after placement of orphaned children with relatives] result in that the children end up being abused and ill-treated, and social workers, you find that they are not aware ...

... because we are not able to visit them to do supervision ... you find that the children ... leave those placements ...

Because of the lack of supervision and monitoring of placements by social workers, extended family members felt unsupported, as expressed in the following statement:

... the government will just give the children grants and then stand very far from the children. The government doesn't know how we feel when we take care of these children 


\section{Category: High turnover of social workers as a hindrance to integrating the CHH into the extended family}

Because of the high turnover of social workers, newly appointed social workers were unaware of placements that required supervision as a result of a lack of proper handover procedures from the exiting social workers. The following statements from two social workers attest to this:

... there is a huge turnover of social workers in our office ...

Sometimes our services are disjointed, when a social worker resigns or gets transferred, there is no proper handover to the new social worker who is taking over the office, and it becomes difficult for the new social worker to know where to begin cases that need supervision ...

The findings presented in this sub-theme were consistent with the findings from the situational analysis of $\mathrm{CHH}$ in South Africa (Department of Social Development, 2008:26) that there is a high turnover of social workers, especially in the rural areas, and the social workers are seldom helpful and are not supportive when organisations report cases of $\mathrm{CHH}$.

\section{CONCLUSIONS AND RECOMMENDATIONS PERTAINING TO FURTHER AND FUTURE RESEARCH}

The barriers to the integration of $\mathrm{CHH}$ back into the fold of the extended family as articulated by the participants in this research project led the researchers to the conclusion that the aims and efforts of integrating orphaned children from $\mathrm{CHH}$ into the fold of the extended family are complex, multifaceted and multi-sphered. This study found that the barriers that hinder the integration of orphaned children into extended families go beyond the latter's economic capacity to absorb orphaned children into their homes and include barriers that are related to poverty, relational and family issues, and cultural practices, as well as barriers related to the circumstances of the orphaned children. Social workers are perceived to be key delivery agents in the integration process. The limitations in social work service delivery also posed a huge challenge in the integration process because poor quality service delivery, especially through lack of support to family integration placements, led to the disintegration of family placements.

Based on these findings, the following strategic interventions are recommended to improve the efficacy of the integration of orphaned children into extended family folds.

- Provide extended families with poverty relief support.

- The Social Assistance Act (Act No. 13 of 2004) should be reviewed to introduce a family grant that will cater for the extended families which take in orphaned children.

- Parenting programmes are recommended to support the extended families who have taken in orphaned children.

- Continuous family therapy sessions are recommended for the extended families who have taken in orphaned children to help them cope with the additional responsibility of taking in orphaned children.

- A further recommendation is for the development and implementation of succession planning programmes by social workers and NGOs to assist biological parents to plan for the future of their children before they pass on. 
- The participation of the orphaned children and the extended family's biological children in making decisions which will directly affect their lives should be encouraged.

- In view of the shortage of social workers in rural areas and the need for supervision and monitoring of the extended families where children are placed with relatives, continuous professional development training for social auxiliary workers is recommended to train them with a view to utilising them to supervise and monitor the placements of orphaned children with their relatives.

The following recommendations for further and future research are proffered.

- Further qualitative studies are needed to gain an in-depth understanding of the factors that lead to the disintegration of family placements from the perspectives of orphaned children who were previously integrated with their extended families, as well as these extended families' perspectives.

- There is a need for a comparative study involving the orphaned children and the biological children of the extended families to explore how treatment is effected regarding the children in family placements.

\section{REFERENCES}

AMOATENG, A.Y. \& RICHTER, L.M. 2007. Families and households in post-apartheid South Africa: socio-demographic perspectives. Cape Town: HSRC.

CHILD CARE ACT NO 74 of 1983. Pretoria: Government Printer.

CHILDREN'S AMENDMENT ACT No 41 of 2007. Pretoria: Government Printer.

COMMUNITY SURVEY. 2007. [Online] Available: http://www.statssa.gov.za/ community_new/ content.asp. [Accessed: 26/06/2009].

CRESWELL, J.W. 2003. Research design: qualitative, quantitative, and mixed methods approaches. London: Sage Publications.

DEPARTMENT OF SOCIAL DEVELOPMENT. 2008. A situational analysis of childheaded households in South Africa. Pretoria: Government Printer.

DONALEK, J.G. \& SOLDWISCH, S. 2004. Demystifying nursing research: an introduction to qualitative research methods. Urologic Nursing, 24(4):354-356.

FOSSEY, E., HARVEY, C., McDERMOTT, F. \& DAVIDSON, L. 2002. Understanding and evaluating qualitative research. Australian and New Zealand Journal of Psychiatry, 36:717732 .

FOSTER, G., MAKUFA, C., DREW, R. \& KRALOVEC, E. 1997. Factors leading to the establishment of childheaded households: the case of Zimbabwe. Health Transmission Review, 2(7):155-168.

FOSTER, G. 2000. The capacity of the extended family safety net for orphans in Africa. Psychology, Health \& Medicine, 1(5):55-62.

FOSTER, G. 2004. Safety nets for children affected by HIV/AIDS in Southern Africa, Monograph, 109.

GERMANN, S.E. 2005. An exploratory study of quality of life and coping strategies of orphans living in child-headed households in the high HIV/AIDS prevalent city of 
Bulawayo, Zimbabwe. Pretoria: University of South Africa Pretoria. (Unpublished DPhil Dissertation)

GILBORN, L.Z., NYONYINTONO, R.K. \& JAGWE-WADDA, G. 2001. Making a difference for children affected by AIDS: baseline findings from operations research in Uganda. Washington DC: The Population Council.

GREEN, J. \& THOROGOOD, N. 2009. Qualitative methods for health research ( $\left.2^{\text {nd }} e d\right)$. London: Sage Publications.

HOWARD, B.H., PHILliPS, C.V., MATINHURE, N., GOODMAN, K.J., McCURDY, S.A. \& JOHNSON, C.A. 2006. Barriers and incentives to orphan care in a time of AIDS and economic crisis: a cross-sectional survey of caregivers in rural Zimbabwe [Online] Available: http://www.biomedcentral.com/content/pdf/1471-2458-6-27.pdf [Accessed: 21/02/2010.]

KREFTING, L. 1991. Rigor in qualitative research: the assessment of trustworthiness. The American Journal of Occupational Therapy, 45(3):214-222.

MacLELLAN, M. 2005. Child headed households: dilemmas of definition and livelihood rights. Coventry University: African Studies Centre.

MKHIZE, Z.M. 2006. Social functioning of a child-headed household and the role of social work. Pretoria: University of South Africa. (Unpublished DPhil Dissertation)

MPUMALANGA DEPARTMENT OF HEALTH AND SOCIAL SERVICES. 2007. HIV prevalence survey results 2007. Nelspruit: Planning, information, research \& epidemiology.

NEUMAN, W.L. 2006. Social research methods: qualitative and quantitative approaches $\left(6^{\text {th }}\right.$ ed). Boston: Pearson Education Inc.

NKOMO, N. 2006. The experiences of children carrying responsibility for child-headed households as a result of parental death due to HIV/AIDS. Pretoria: University of Pretoria. (Unpublished MA Dissertation)

PATEL, L. 2005. Social welfare and social development in South Africa. Cape Town: Oxford University Press Southern Africa.

PHIRI, S.N. \& TOLFREE, D. 2005. Family- and community-based care for children affected by AIDS: strengthening the front line response. In: FOSTER, G., LEVINE, C. \& WILLIAMSON, J. (eds) A generation at risk: the global impact of HIV/AIDS on orphans and vulnerable children. New York: Cambridge University Press.

RANTLA, M., SIWANI, J. \& MOKOENA, N. 2002. Orphans and extended families reintegration pilot project report. Johannesburg: National Children's Rights Committee.

THE SOCIAL ASSISTANCE ACT No 13 of 2004. Pretoria: Government Printer.

YEGIDIS, B.L. \& WEINBACH, R.W. 2002. Research methods for social workers $\left(4^{\text {th }}\right.$ ed). Boston: Allyn \& Bacon.

Ms Luzile Florence Nziyane, Deputy Director, Department of Social Development, Pretoria; Prof Assim Hashim Alpaslan, Department of Social Work, University of South Africa, Pretoria, South Africa. 